\title{
A formação profissional do fisioterapeuta para atuar na equipe de assistência ao parto humanizado: a visão do aluno de uma universidade pública
}

\section{Professional formation of physical therapist to act on assistance team to humanized birth: the student's vision of a public university}

\author{
${ }^{1}$ Rafaela Comaru Gouveia rafaela_comaru@yahoo.com.br \\ 2 Renato da Costa Teixeira \\ ${ }^{3}$ Robson José de Souza Domingues \\ ${ }^{4}$ Marília da Silva Pinheiro \\ ${ }^{5}$ Emmanuel Ribeiro Cunha
}

\section{RESUMO}

O estudo trata da formação do profissional fisioterapeuta para atuar na assistência ao parto humanizado. A pesquisa qualitativa e descritivo teve como objetivos analisar as percepções dos estudantes de fisioterapia da Universidade do Estado do Pará (UEPA) sobre o atendimento fisioterapêutico a mulheres em trabalho de parto e apontar alternativas para melhorar a formação do fisioterapeuta para atuar na equipe de assistência ao parto humanizado. Contou com a participação de 20 alunos que responderam a um questionário e participaram de grupos focais. Os resultados demonstraram que os alunos detêm os conceitos relacionados à humanização, no entanto não revelaram conhecimentos específicos sobre as políticas do Ministério de Saúde de assistência humanizada ao parto. As disciplinas que abordam a assistência humanizada ao parto estão no caminho certo, ainda que melhorias possam ser realizadas. Propõe-se estratégias para melhorar a formação inicial do fisioterapeuta.

Palavras-chave: Ensino em saúde. Fisioterapia. Parto. Humanização em saúde.

\section{ABSTRACT}

The study is about the formation of the physiotherapist to work in humanized birth care. A qualitative descriptive research aimed to analyze the perceptions of physical therapy students from Universidade Estadual do Pará (UEPA) on the care of the physiotherapist to women in labor, and proposes other ways to improve the experience of students in the area of physiotherapy in humanized childbirth care. Twenty 20 students responding to a questionnaire and participating in focal groups. The results showed that students know the concepts related to humanization, however revealed no specific knowledge about the policies of Ministry of Health of Brazil regarding humanized childbirth care. The disciplines that address the humanized childbirth care are on the right track, although improvements can be made. It is proposed strategies to improve the initial training of Physiotherapist.

Keywords: Health education in physical therapy. Humanized birth. Health humanization.

1 Fisioterapeuta; Mestre em ensino em saúde na Amazônia; Programa de pós-graduação Ensino em Saúde na Amazônia, Universidade do Estado do Pará.

2 Fisioterapeuta; Doutor em Educação; Departamento de Ciências do Movimento Humano; Programa de pós-graduação ensino em saúde na Amazônia, Universidade do Estado do Pará.

3 Biólogo; Doutor em Ciências Biológicas; Departamento de Morfologia; Programa de pós-graduação ensino em saúde na Amazônia, Universidade do Estado do Pará.

4 Médica; Mestre em ensino em saúde na Amazônia; Programa de pós-graduação Ensino em Saúde na Amazônia, Universidade do Estado do Pará.

5 Pedagogo; Doutor em Educação; Programa de pós-graduação Ensino em Saúde na Amazônia, Universidade do Estado do Pará. 


\section{INTRODUÇÃO}

Os alunos de fisioterapia necessitam aprender durante o curso de graduação os benefícios que os procedimentos fisioterapêuticos podem proporcionar sobre as atividades funcionais da mulher no período do parto. É necessário incorporar nos currículos conhecimentos, habilidades e atitudes sobre os procedimentos da fisioterapia sobre a circulação, respiração, analgesia, deambulação, atividade intestinal das mulheres grávidas, a fim de que o fisioterapeuta, juntamente com os membros de assistência ao parto, possa melhorar o bem estar da mulher no pré-parto, parto e pós-parto.

No curso de fisioterapia da Universidade do Estado do Pará, os conhecimentos sobre assistência ao parto são trabalhados nas disciplinas Fisioterapia na saúde da mulher e Estágio preliminar I: saúde e disfunções da mulher. Porém ainda parece muito pouco para a importância e dimensão do problema vivenciado de violação dos direitos da parturiente. Esses direitos que são assegurados na Lei Orgânica da Saúde (LOS) 9.090/1988, na Política de Atenção Integral à Saúde das Mulheres (PAISM), no Programa de Humanização do Pré-Natal e Nascimento (PHPN), na Política Nacional de Atenção Obstétrica e Neonatal (PNAON) e no mais recente Programa Rede Cegonha, portanto, temos o desafio de melhorar a formação para que os preceitos da humanização no parto sejam uma realidade.

O ato fisiológico de parir e nascer passou a ser visto como patológico, perigoso e portanto, institucionalizado, requerendo o uso excessivo de tecnologia, com técnicas intervencionistas despersonalizadas e procedimentos invasivos muitas vezes desnecessários, sem respeito à autonomia da mulher e à participação da família, culminando na "desumanização da assistência ao parto" e consequentemente num momento traumatizante para a mulher (BRASIL, 2001; CASTRO e CLAPIS, 2005; MOURA et al., 2007; SEILBERT et al., 2005).

Não se pode negar que a evolução tecnológica da medicina voltada ao alívio da dor e à redução dos riscos da parturição proporcionou avanços inquestionáveis na qualidade da assistência obstétrica, no entanto representou também um elemento importante no processo de medicalização do parto e do nascimento, violando muitas vezes os direitos da parturiente.

A proposta de humanização da assistência ao parto busca elevar a mulher a sujeito deste processo, valorizar o caráter fisiológico e cultural deste momento, redefinir as relações humanas e enfatizar a importância do suporte psico-afetivo (DIAS; DESLANDES, 2006; DINIZ, 2005).

Um documento produzido pelo Ministério da Saúde (MS) sobre a assistência humanizada à mulher (BRASIL, 2001, p. 15) afirma que "pensar sobre a mulher e sua saúde é pensar uma nova sociedade, em que o eixo central seja a qualidade de vida".

No contexto atual de atendimento em saúde, humanização é compreendida como a capacidade de ofertar atendimento de qualidade aliando avanços tecnológicos, acolhimento, ambientes adequados, boas condições de trabalho para os profissionais e desta forma representa um desafio, sendo tema amplamente discutido e ocupando lugar de destaque entre as propostas de reconstrução das práticas de saúde no Brasil (AYRES, 2005; BRASIL, 2000; BRASIL, 2004; SILVA E SILVEIRA, 2011).

Neste sentido, o tema humanização é considerado um enfoque fundamental para a formação do trabalhador da saúde em busca do cuidado integral e da promoção desta, enfatizando a subjetividade e a dimensão social de cada sujeito envolvido no processo de saúde-doença-cuidado (CASATE e CORRÊA, 2012).

Este caminho em direção ao aprimoramento da formação tem sido percorrido por diversas profissões da área da saúde (MOYSÉS et al, 2003; ROSSONI e LAMBERT, 2004; REGO; GOMES e SIQUEIRA-BATISTA, 2008; LIMA, 2009; ERDMANN, et al., 2009; MORETTI-PIRES e BUENO, 2009; SUMIYA e JEOLÁS, 2010; SILVA; CHENICHARO e FERREIRA, 2011; CASETE e CORRÊA, 2012), demonstrando assim que há 
necessidade de maior empenho das instituições formadoras neste sentido, e no que tange a área da fisioterapia que tem a sua origem histórica relacionada ao nível terciário (RIBEIRO, 2005) - esse é um percurso ainda mais complexo.

Quanto à humanização da assistência ao parto, para Diniz (2005), está relacionada a uma gama de interpretações e a um conjunto amplo de propostas de mudança nas práticas, trazendo novos e desafiadores conceitos.

Para Tornquist (2007), o conjunto de medidas tidas como humanizadoras do parto buscam desestimular o parto medicalizado, com intervenções excessivas, que tornaram esse momento natural em algo artificial e violento, e incentivar práticas que respeitem sua fisiologia e biomecânica.

A OMS (2009) recomenda que sejam utilizadas medidas não farmacológicas e não invasivas de alívio da dor, tais como massoterapia e técnicas de relaxamento, enfatizando a importância do apoio empático da equipe, do estímulo a posições não supinas durante o trabalho de parto e do direito a informações e de escolha.

O Fisioterapeuta, profissional que estuda em sua formação acadêmica a biomecânica do corpo humano, está habilitado para prescrever, nestas circunstâncias, a utilização de recursos não farmacológicos e não invasivos que são capazes de favorecer um trabalho de parto ativo, natural, conforme aconselhado pela OMS (2009). Bavaresco et al. (2011), confirmaram em seu estudo que a atuação do fisioterapeuta pode contribuir para a abreviação da duração do período expulsivo, redução de intervenções e de dor durante o parto.

Porém, na prática, observa-se que a participação do fisioterapeuta na assistência ao parto ainda é desconhecida pela maioria dos profissionais de saúde e pela população (CASSOL; CANFIELD e MORAIS, 2001; MAZZALI e GONÇALVES; 2008), e a maioria dos hospitais ainda não oferece esse atendimento. Para que essa atuação seja bem estabelecida e reconhecida, é necessário que a formação do profissional fisioterapeuta contemple essa realidade.

A Universidade do Estado do Pará (UEPA) é mantenedora de um curso de Fisioterapia, que em sua organização curricular está fundamentada em três diretrizes filosóficas básicas: o vínculo entre teoria e prática, no qual o homem deve estar inserido em seu contexto bio-psico-social, valorizando-se a atenção integral a saúde; na compreensão da realidade de forma materialista-histórica-dialética, ou seja, do homem como ser capaz de transformar o mundo, e por ele ser transformado; e de incentivo à pesquisa científica como um processo dinâmico de construção do conhecimento, que através de uma visão crítica, reflexiva, analítica e criativa busque intervir na realidade.

A matriz curricular deste curso contempla conteúdos relacionados à atuação do fisioterapeuta em saúde da mulher, em duas disciplinas Fisioterapia na saúde da mulher e Estágio Preliminar I: Saúde e disfunções da mulher.

Em nossa experiência como docente das disciplinas que contemplam os conteúdos voltados a fisioterapia aplicada a saúde da mulher, pudemos constatar que muitas vezes as práticas voltadas para atuação do fisioterapeuta na assistência ao parto humanizado ficam prejudicadas, em função da pouca disponibilidade de tempo e de oportunidades, uma vez que depende da existência de parturientes no período de aula, além disto, é uma atividade totalmente diferenciada, na qual é fundamental o respeito a fisiologia do parto, sendo assim é necessário reduzir o número de pessoas presentes na sala de parto (dois estudantes e um professor), reduzindo a oportunidade dos estudantes estarem no centro obstétrico no momento do parto.

Assim, a questão colocada para estudo foi: como os estudantes de fisioterapia avaliam a formação obtida para atuar na assistência ao parto humanizado? 
O estudo proposto teve o objetivo de analisar a percepção dos estudantes de fisioterapia da UEPA sobre o atendimento do fisioterapeuta a mulheres em trabalho de parto; e apontar alternativas para melhorar a formação do fisioterapeuta para atuar na equipe de assistência ao parto humanizado.

\section{DESCRIÇÃO DO PERCURSO METODOLÓGICO}

Tratou-se de um estudo realizado para obtenção do título de Mestre em Ensino em Saúde na Amazônia, caracterizado como qualitativo de caráter descritivo, através da técnica de coleta de dados por grupo focal. Conforme Ludke e André (2012), o estudo qualitativo busca capturar a perspectiva dos participantes sobre as questões avaliadas, considerando diferentes pontos de vista e permite conhecer mais aprofundadamente as situações analisadas. Para esses autores, na pesquisa qualitativa a fonte de dados é o ambiente natural e o principal instrumento é o pesquisador, que deve estudar o fenômeno em seu ambiente natural sem manipulá-lo, sendo considerado assim, por estes autores como um estudo naturalístico.

O contexto da pesquisa foi o Curso de Fisioterapia da UEPA no qual a atuação da fisioterapia em saúde da mulher é abordada nos sétimo e oitavo semestres pelas disciplinas Fisioterapia na saúde da mulher e Estágio Preliminar I: Saúde e disfunções da mulher (PARÁ, 2012).

O estudo foi realizado com os alunos do oitavo semestre do curso que totalizavam 35 alunos, respeitando os preceitos da Declaração de Helsinque, Código de Nuremberg e as Normas de Pesquisa em Seres Humanos (Resolução CNS 466/12) do Conselho Nacional de Saúde, tendo sido aprovado pelo Comitê de Ética em Pesquisa do Campus II da UEPA, parecer $n^{\circ}$ 500.602. Os participantes assinaram o Termo de Consentimento Livre e Esclarecido (TCLE) antes de participar do grupo focal.

O total de alunos matriculados no oitavo semestre eram 30. Destes, 23 responderam ao questionário e declararam ter acesso à informação sobre o parto humanizado e ter interesse em participar da pesquisa voluntariamente. Isto possibilitou a utilização da técnica de entrevista do tipo grupo focal.

De acordo com Gatti (2005), a técnica de grupo focal permite desvelar a opinião de um determinado grupo social sendo uma ferramenta útil quando que se quer analisar o grau de consenso a respeito de um assunto, representando também uma forma de evidenciar a percepção de diferentes sujeitos, a compreensão de ideias cotidianas partilhadas, além de encorajar o diálogo a respeito de questões embaraçosas, polêmicas, complexas e de difícil abordagem, como era o caso deste estudo.

Martins e Bógus (2004) acrescentam que o grupo focal permite um contato pessoal entre pesquisador e os sujeitos, e assim, o surgimento de respostas inesperadas levantando percepções e novas ideias.

Após a caracterização do perfil dos 23 alunos que responderam ao questionário, 20 aceitaram participar do grupo focal, sendo subdivididos em quatro grupos, um grupo com seis, dois grupos de cinco, e um grupo de quatro participantes.

As discussões ocorreram em sala fechada e foram gravadas em áudio por dois gravadores dispostos pela sala, conforme orientado por Gatti (2005). As interações foram conduzidas pela própria pesquisadora que também fazia o registro das falas manualmente, seguindo o roteiro de forma flexível de modo a realizar direcionamentos ao tema, facilitando as trocas.

O tempo de duração dos encontros foi em média de 56 minutos. Posteriormente as gravações foram transcritas e compatibilizadas com as anotações a fim de compor um material mais completo possível para a análise. Os estudantes receberam uma codificação de E1 a E20 para preservar seu anonimato. 
O processo de análise dos dados foi realizado concomitantemente à coleta de dados e teve início após o primeiro encontro, de forma que pudesse contribuir para o encaminhamento das sessões subsequentes, evidenciando pontos a serem esclarecidos ou melhor abordados.

A análise foi realizada a partir da construção de um plano descritivo das falas através da técnica de análise de conteúdo modalidade temática, que de acordo com Bardin (2011), caracteriza-se como uma metodologia de pesquisa constituída por um conjunto de técnicas de investigação que "através de uma descrição objetiva, sistemática e quantitativa do conteúdo manifesto das comunicações tem por finalidade a interpretação destas mesmas comunicações” (BARDIN, 2011, p. 38).

Para tanto, foi realizada a escuta exaustiva das gravações e leitura das anotações buscando uma aproximação das situações e assim proceder a apreciação dos sentidos, de acordo com Gatti (2005). Buscou-se ressaltar o que foi relevante em cada discussão, agrupando percepções afins, comparando opiniões, explorando tanto posicionamentos majoritários quanto os minoritários a fim de serem obtidas inferências. Os achados foram confrontados com os referenciais teóricos que sustentam o estudo.

\section{RESULTADOS E DISCUSSÃO}

Em relação perfil dos 23 respondentes iniciais, na tabela 1 podemos observar a distribuição da faixa etária onde evidencia-se que a maioria dos estudantes ingressou na Universidade muito jovem considerando-se que estavam no oitavo semestre letivo.

Tabela 1 - Faixa etária dos estudantes

\begin{tabular}{ccc}
\hline Idade & Quantidade & Percentual \\
\hline 20 a 25 & 19 & $83 \%$ \\
26 a 30 & 2 & $9 \%$ \\
31 a 35 & 1 & $4 \%$ \\
36 a 40 & 0 & $0 \%$ \\
41 a 43 & 1 & $4 \%$ \\
\hline
\end{tabular}

Fonte: Formulário de pesquisa, 2014.

A tabela 2 demonstra que há uma predominância de mulheres na turma estudada.

Tabela 2 - Distribuição dos respondentes por sexo

\begin{tabular}{ccc}
\hline Gênero & Quantidade & Percentual \\
\hline Feminino & 15 & $65 \%$ \\
Masculino & 8 & $15 \%$ \\
\hline
\end{tabular}

Fonte: Formulário de pesquisa, 2014.

Na tabela 3 podemos constatar que a maioria dos estudantes referiram afinidade com a área de fisioterapia aplicada à saúde da mulher, o que comprova que conseguimos alcançar uma amostra composta em sua maioria por participantes que tem interesse/afinidade pelo conteúdo que se quer pesquisar. 
Tabela 3- Afinidade com a área de Fisioterapia aplicada a Saúde da Mulher

\begin{tabular}{ccc}
\hline Variáveis & Quantidade & Percentual \\
\hline Sem afinidade & 1 & $4 \%$ \\
Pouca afinidade & 7 & $30 \%$ \\
Indiferente & 2 & $9 \%$ \\
Média & 8 & $35 \%$ \\
afinidade & & \\
Muita afinidade & 5 & $22 \%$ \\
\hline
\end{tabular}

Fonte: Formulário de pesquisa, 2014.

A assistência fisioterapêutica na saúde da mulher é reconhecida pelo Conselho Federal de Fisioterapia e Terapia Ocupacional como especialidade pela Resolução 372 de 06 de novembro de 2009 e Resolução 401 de 18 de agosto de 2011, cabendo a este profissional a avaliação, prevenção, promoção através de condutas fisioterapêuticas nas alterações cinesiofuncionais advindas do ciclo menstrual, climatério, parturientes, puérperas e secundários ao comprometimento oncológico.

As áreas de atuação do Fisioterapeuta Especialista Profissional em Fisioterapia na Saúde da Mulher são de acordo com as Resoluções citadas, entre outras: Assistência fisioterapêutica em uroginecologia e coloproctologia, assistência fisioterapêutica em ginecologia, assistência fisioterapêutica em obstetrícia, assistência fisioterapêutica nas disfunções sexuais femininas, assistência fisioterapêutica em mastologia, tanto a nível ambulatorial, domiciliar, hospitalar em todos os níveis de atuação em saúde.

Em relação a atuação do fisioterapeuta na equipe de assistência ao parto humanizado, esta não está estabelecida nos programas e ações do MS e ainda é uma realidade pouco frequente.

No entanto, o fisioterapeuta, atuando na equipe, pode contribuir para uma melhor assistência ao parto humanizado, uma vez que favorece o uso de medidas não farmacológicas e não invasivas para proporcionar conforto à paciente. Bio (2007) ao comparar o efeito da intervenção fisioterapêutica na assistência ao trabalho de parto, entre dois grupos de parturientes que evoluíram para o parto vaginal com e sem intervenção fisioterapêutica, concluiu que a ação das condutas fisioterapêuticas sobre a estrutura osteoarticular facilita a progressão do trabalho de parto na fase ativa, promove a evolução da dilatação e favorece o parto vaginal.

Quando interrogados sobre a importância das disciplinas voltadas para saúde da mulher na sua formação acadêmica todos estudantes concordaram que foram muito relevantes para a sua formação profissional, um fato muito comentado foi que, ainda que a área de atuação futuramente pretendida seja outra, muitas vezes surgirão questões relacionadas a saúde da mulher, e que estas devem também receber atenção como pode ser observado nos relatos seguintes.

Extremamente importante, por que praticamente metade do público que a gente atende são mulheres, de várias faixas etárias, então fisioterapia na saúde da mulher ela pode estar atuando em diversas fases da mulher e atendendo pacientes de uma forma global, não só aquela patologia que ele tá reclamando no momento, que pode não tá referindo a saúde da mulher, mas ele pode ter um problema que a gente pode resolver no momento, então eu acho extremamente importante. (E9)

É importante por que independente da área que a gente quer atuar, pretende ou vai atuar, a gente vai ter pacientes mulheres, vai ter uma paciente com uma determinada patologia referente a saúde da mulher então é importante a gente saber mesmo tratar e como lidar com essas situações. (E19) 
A partir dos relatos percebe-se que os estudantes conseguiram apreender o significado, amplitude e complexidade dos temas tratados pelas disciplinas, despertando também para a atenção integral da assistência em saúde, contrastando com o descrito por Petri (2006), de que a formação de fisioterapeutas atribui pouca relevância a temas sociais.

(...) quando a gente lida com mulheres a gente observa vários tipos de problemas, não só o problema que ela vai relatar, não é só uma incontinência, ou uma fraqueza de musculatura mas também com relação a outros aspectos, sociais por exemplo, a... violência contra a mulher, um exemplo muito clássico... (E6)

O fisioterapeuta pode estar inserido na atenção primária e secundária como parte da equipe multiprofissional de saúde de modo a preparar e orientar a gestante sobre questões referentes ao processo gestacional, modificações corporais e emocionais, trabalho de parto, parto e puerpério, cuidados com o bebê e amamentação, conforme preconiza o Ministério da Saúde no contexto da humanização do nascimento. De acordo com Andrade e Lima (2014, p.37) o apoio físico e emocional a parturiente "pode ser oferecido à mulher tanto pelo seu acompanhante ou doula, assim como pelos profissionais que participam da assistência (auxiliares e técnicos em Enfermagem, psicólogos, enfermeiros, médicos, fisioterapeutas, entre outros)” (BRASIL, 2001).

Contudo, a atuação da fisioterapia na assistência ao parto humanizado não é conhecida pelos estudantes de fisioterapia que ainda não cursaram as disciplinas voltadas para área de saúde da mulher, o que se verifica no seguinte relato:

(...) antes de passar pelo módulo eu sinceramente não tinha conhecimento da atuação do fisioterapeuta na sala de parto principalmente, nos momentos antes, naquele momento que ela esta esperando a dilatação, que a professor leva a gente no PPP, tantas orientações que pode passar pra parturiente naquele momento, as vezes por ela não ter informação nenhuma e a gente sabe depois que a gente passa, depois que a gente estuda, depois que a gente vê como realmente é, tantas coisas que podem fazer pra amenizar a dor e até mesmo pra acelerar o processo de dilatação e passar mais rápido também, então pra mim foi um aprendizado muito grande poder conhecer isso e vivenciar principalmente. Então pra mim foi muito importante. (E12)

A maioria dos estudantes demonstrou que detém os conceitos relacionados ao parto humanizado, como o respeito à autonomia, direito à informação, à importância da presença do acompanhante, de utilização de recursos não invasivos, dos benefícios da assistência fisioterapêutica durante o parto e referiram que alguns profissionais da equipe do hospital onde as atividades práticas ocorreram relatam que a atuação da fisioterapia reduz o uso de drogas e favorece o trabalho de parto, como demonstrado:

Outra coisa também que a gente ajuda é na redução do uso de medicamentos, que quando a gente estava lá os próprios enfermeiros e outros profissionais disseram isso pra gente que eles usam menos medicamentos quando nós entramos, até pro alívio de dor, eles relataram, ajuda no período da expulsão, aumenta a dilatação, principalmente para as primigestas e eu também achei bem interessante que a gente evita laceração e a episiotomia. O que é bem recorrente e vai causar uma série de problemas posteriormente pra essa mulher, então a fisioterapia na sala de parto, tem esse benefício. (E2)

Quando questionados a respeito da contribuição das aulas e tarefas desenvolvidas para a sua formação profissional, os estudantes foram unânimes ao descrever que as atividades ofertaram conhecimento e vivências importantes para sua vida profissional, houve uma boa fundamentação teórica, sentiram-se mais seguros em relação à interação com a paciente e elaboração do plano de tratamento, como segue: 
Pra mim é... foi super positivo por que a gente tava lá dentro ... as aulas deu pra mostrar bem o que é que a fisioterapia faz na sala de parto, eu acho que só o negativo é por que a gente ainda não tem o espaço que deveria ter e as vezes a gente vai lá e não tem paciente, mas as aulas são bem dinâmicas, foi bem explicado pela professora, um bom suporte teórico, mas acho que só na prática mesmo que a gente sabe o que fazer, como atuar, de que forma atuar, acho que foi muito positivo. (E8)

Com relação à avaliação da formação para atuar como profissional na assistência ao parto humanizado, os estudantes ficaram divididos, houve relatos de pessoas que se sentem seguras e aptas para atuar na área, com a ressalva de que percebem que tem ainda pouca experiência prática, mas que detém o conhecimento básico necessário para prestar assistência. Houve relatos que afirmaram que a pessoa que deseja seguir esta linha de atuação deve realizar pós-graduação específica, e um caso de um participante que descreveu que não se sente confortável em atuar na área apesar de ter considerado que detém o conhecimento.

Também foram reveladas percepções que consideraram sua formação como deficitária, uma vez que avaliaram o tempo de prática curto para adquirir uma experiência que lhes proporcione segurança para atuação como profissional. Por outro lado, um participante considerou que a formação não é uma responsabilidade apenas da Universidade, uma vez que o estudante também deve buscar o conhecimento, com isso surgiu a discussão a respeito da falta de oportunidades de estágio na área, uma vez que, como já foi descrito, há poucos fisioterapeutas atuando nas salas de parto em Belém.

A concepção de que o parto é um evento que tem influencia de fatores sociais e emocionais, além dos físicos, que se desenrolam ao longo da vida da mulher, esteve presente em algumas falas, além da ideia de que o fisioterapeuta pode e deve atuar também na preparação para o parto, pré-natal e pós-parto, conforme descrito na literatura (BARACHO, 2012; BRANDÃO; GASPARETTO e PIVETTA, 2008; CIRNE, 2009; SOUZA et al., 2005; STEPHENSON, O'CONNOR; 2004). Isto demonstra que os alunos conseguiram compreender os conteúdos discutidos, conforme o pretendido pelas disciplinas.

Apesar do exposto, houve um estudante que criticou a metodologia utilizada pelas disciplinas ministradas no sétimo e oitavo semestres da graduação, uma vez que considerou que a divisão da carga horária é realizada entre as atividades de teoria e prática atrapalhando o aprendizado, comentário que foi corroborado pelos outros participantes do grupo:

\footnotetext{
“A minha opinião ela não vale só pra essa disciplina, vale pra várias, mas de fato isso pode até ser um problema no nosso projeto, a gente chega no quarto ano a gente não tem nem totalmente prática nem totalmente teoria, a gente fica deficitário nos dois lados, a gente pega Saúde da Mulher por exemplo, a gente entra lá, já entra naquela pressão, a mulher tá quase pra ter um filho ali na minha frente e eu aqui nunca vi isso aí acontecer, as vezes o professor está pressionando, a gente já tem que chegar sabendo, dependendo do que a gente fizer a gente pode pegar (impublicável) a qualquer momento.” Uma coisa é a teoria, é linda, mas na prática tudo pode acontecer ali, naquele momento. (E13)
}

A carga horária das disciplinas que tratam da atuação da fisioterapia na assistência a mulher é dividida entre as aulas teóricas e as atividades práticas. No que se refere às atividades práticas direcionadas à assistência fisioterapêutica ao trabalho de parto, os estudantes referiram que foi uma experiência muito positiva para seu crescimento profissional, e que foi possível fazer a relação do que foi discutido na teoria em sala de aula com a prática nas salas de parto, conforme segue: 
... do meu ponto de vista eu acho quando nós estávamos presentes era uma força a mais, uma presença a mais, mas uma presença que faz a diferença, que você pega, que você anda, vem cá, vem ajudar, tu chama o pai, vem cá, olha tu não tem que ficar sentado aí, você tem que estar ao lado dela, faz massagem nas costas, faz massagem no baixo ventre, ensina a alongar... Aconteceram coisas assim, não comigo por que eu não tive essa experiência de assistir um nascimento, mas os dois que tiveram a oportunidade, choraram! Por que foi extraordinário, foi uma coisa assim, geralmente na primípara o trabalho de parto é demorado, 12 horas, 14, 20, até 24 horas... e aconteceu deles entrarem e a moça estar com $5 \mathrm{~cm}$ de dilatação e eles ficaram ate 17 horas da tarde e a moça teve o bebê, ai eu fiquei pensando será que foi a presença deles? Será que foi o estímulo, foi a ajuda, foi o trabalho que eles tiveram com ela? Ninguém pode saber... o fato é que aconteceu! O bebê nasceu e ficou todo mundo emocionado! Eu considero que é importantíssimo a presença desse profissional dentro da sala, dentro do PPP. (E14)

Com o intuito de contribuir buscando melhorias para a formação, os estudantes foram questionados a respeito de dificuldades e sugestões para que as atividades práticas relacionadas à assistência ao parto humanizado pudessem ser aperfeiçoadas e referiram a questão de falta de espaço físico e também de espaço enquanto profissional da equipe, uma vez que no hospital onde as práticas acontecem não há profissional fisioterapeuta atuando dentro da equipe de assistência ao parto humanizado, conforme demonstrado a seguir:

Como a gente ainda não tem o espaço definido era muito assim... dá tempo de entrar agora? Então bora lá, aí chegou a enfermeira, sai, ai pede pra esperar um pouquinho, vê o que da pra fazer naquele tempo e talvez se já tivesse esse o fisioterapeuta, talvez, apesar de que o horário em hospital é meio corrido, o nosso papel pra nós já é definido, mas se o nosso lugar já estivesse definido lá talvez isso facilitasse o nosso trabalho. (E17)

Com relação à falta de espaço na equipe para realizar a assistência, um estudante referiu que houve até um desconforto com a equipe, situação que possivelmente possa ter ocorrido pela pouca aceitação dos alunos no ambiente de trabalho, ou até mesmo pela pouca aceitação da presença de um profissional que não compõe a equipe rotineiramente.

\footnotetext{
O ponto negativo é mesmo a questão da falta de apoio lá dentro, a forma como os outros profissionais que tão lá olham pra a gente, eu acho que as vezes quando a gente chega lá querendo ou não a gente causa um certo desconforto, com relação aos outros profissionais, tem alguns que contribuem mesmo, por exemplo, uma acadêmica foi lá e contribuiu mesmo, conversou, passou todas as informações da paciente, enquanto que as outras enfermeiras sequer olharam pra a gente, quando a gente estava com o prontuário, já queriam puxar o prontuário pra evoluir... (E6)
}

Dias e Deslandes (2006), em estudo sobre a humanização da assistência ao parto em uma maternidade do SUS que fazia parte do Programa Nacional de Humanização da Assistência Hospitalar (PNHAH), observou que nesse cenário, as enfermeiras ocasionalmente caminhavam com as parturientes e levavam-nas para a banheira e bola de fisioterapia, fato que costuma ocorrer também em outras maternidades. Percebe-se a lacuna existente pela ausência do profissional fisioterapeuta neste ambiente, o que poderia contribuir muito para a assistência humanizada à parturiente, sendo então fundamental que o fisioterapeuta esteja qualificado para exercer sua função nessa área de atuação.

A partir da seguinte fala é possível afirmarmos que para os alunos a presença do profissional fisioterapeuta qualificado poderia contribuir de forma positiva para a melhora da qualidade da assistência prestada: 
(...) a gente desceu pro PPP lá no HC e aí a gente viveu muito isso, a gente chegou a ver um parto, a gente acompanhou a evolução, então a gente aplicou as técnicas, fez as orientações necessárias, e uma coisa muito interessante assim que ficou pra mim é que praticamente ninguém vai lá com aquela paciente. Ela fica meio desamparada, tá lá o acompanhante, mas também sem orientação, sem saber o que fazer. Os enfermeiros, os médicos, eles passam ali, só olham, fazem o toque, mas nada muito íntimo e o tempo que a gente ficou lá a gente pode fazer as coisas que a professora tinha passado pra a gente e muito rapidamente criou-se um vínculo, tanto que na hora que realmente ia acontecer o parto a gente ia se retirar e ela disse: "Não, vocês que ficaram aqui com a gente todo esse tempo vocês ficam." E na hora que ela estava fazendo a força de expulsão, ela não se referia a médica para perguntar, ela olhava pra a gente como ponto referencia, então é mais do que importante, é essencial para a evolução humanizada do parto. (E3)

Outra análise revelada pelos estudantes de forma unânime foi a afirmação de que gostariam de ter mais oportunidades de acompanhar parturientes em trabalho de parto ativo, uma vez que nem todos tiveram essa vivência, visto que dependiam de pacientes nesta situação no dia e horário de aulas práticas, por isso referiram o desejo de mais oportunidades e tempo de permanência durante as práticas para que possa ser realizado o acompanhamento dos partos.

(...) uma vez que eu fiquei a moça tinha entrado já com $8 \mathrm{~cm}$ de dilatação, a gente ficou um tempo lá e não aconteceu nada, e eu achei que uma vez é muito pouco, e também a questão do tempo, por que um trabalho de parto é muito demorado, né e pra a gente ver as nuances, ver realmente tudo o que acontece e poder realmente entender o que a gente faz ali eu acho que a gente precisaria de mais tempo, não só mais vezes como mais tempo. (E11)

Eu acredito que foi bem importante a questão teórica e quanto a prática eu penso que deveria ter um tempo bem maior até, por que quando a gente chega, devido não ter esse conhecimento dessa área, a gente chega lá e já treme na base, já sente muito nervoso, sente inseguro na hora de abordar a paciente, então eu creio que deveria ter um tempo maior pra que a gente pudesse ir mesmo se habituando ao local, aquela própria atuação, só nos últimos dias que nós já ficamos mais a vontade, mas quando a gente vê já acabou a disciplina. Já é hora de ir embora. (E10)

Um estudante sugeriu que o tema "parto humanizado" poderia ser trabalhado antes do sétimo e oitavo semestre da graduação, a fim de que o conhecimento pudesse ser melhor explorado:

É até uma crítica que eu tenho, por que a matriz curricular do curso ela só reserva a questão do parto humanizado a saúde da mulher, sabendo que isso é também uma questão a ser discutida dentro da Fisioterapia Preventiva, ou da Saúde Coletiva. Eu acho que esse debate tinha que vir desde o terceiro ano, pra quando chegar no quarto, quando a gente trabalha mais diretamente com Saúde da Mulher a gente ter um pouco mais de conhecimento, ter mais domínio, saber como abordar, como lidar com a paciente nesse processo. (E6)

Esta é uma sugestão válida, considerando-se que as disciplinas da graduação devem ser ministradas seguindo uma linha de raciocínio que permitam aos estudantes terem embasamento para as disciplinas subsequentes. De acordo com Moreira (2012), a interação entre conhecimentos prévios e conhecimentos novos, em que os novos conhecimentos passam a ter significado para o aluno e os conhecimentos prévios adquirem novos significados é chamada de Aprendizagem Significativa.

Segundo Pellizzari et al (2002) a teoria da aprendizagem significativa foi defendida por Ausubel na década de 1960 e propõe que os conhecimentos prévios dos alunos sejam valorizados, pois assim eles poderão construir estruturas mentais que permitirão descobrir e redescobrir outros conhecimentos, que os levará a uma aprendizagem prazerosa e eficaz.

Os estudantes apontaram ainda como dificuldades, a insegurança ao realizar o atendimento e que o conteúdo deveria ser revisado antes do início das práticas no segundo semestre, conforme a seguir: 


\begin{abstract}
Eu acho que realmente a gente precisa de mais tempo e que haja um retrospecto do professor em estar falando as orientações passadas, enfatizando olha é assim, assim, você vai fazer isso, muitas das vezes o que a gente viu no semestre passado, algumas coisas passam despercebidas, então você chegar lá na sala de parto te deixar lá e falar vai lá! Sem ter aquela orientação antes, só por que você viu no semestre passado e você já tem que saber né e tem que lembrar do que você viu no semestre passado, acho que não é bem assim... né? Acho que a gente deveria sim quando voltar, dizer olha no semestre anterior e ser enfatizado, pra te dar uma segurança maior, até por que vai ser uma segunda vez que você vai estar em contato ali com aquele paciente, né? Por que se você chegar lá e ah meu Deus! Tremendo... vai passar aquela insegurança pra paciente... Então a gente tendo esse retorno no semestre presente né... olha você viram no semestre passado, mas eu estou aqui novamente enfatizando... (E15)
\end{abstract}

Outros estudantes também referiram que se sentiram inseguros. Essa situação pode estar relacionada ao fato de ser um ambiente novo e diferenciado, o que fpode causar um estranhamento aos alunos levando a esta situação.

Apesar do exposto, um dos participantes descreveu que o professor demonstra a humanização através de suas atitudes práticas. Isto evidencia ainda mais o fato de que sua concepção de humanização está intimamente ligada à relação terapeuta-paciente.

Os alunos sugeriram ainda que gostariam de práticas que simulassem o trabalho de parto entre os próprios estudantes antes da realização das práticas no hospital, pois consideram que a teoria é muito distante da realidade e que simular entre eles seria uma forma de prepara-los para a prática na realidade, além disso, propuseram a utilização de vídeos para favorecer a aprendizagem. Estas propostas são facilmente aplicáveis e demonstram que os estudantes têm a capacidade de realizar críticas construtivas e sugestões viáveis a fim de contribuir para a melhoria do aprendizado.

A utilização do cinema como experiência educacional em busca da humanização é defendida por Blasco (2010) como sendo um campo para reflexões, que no seu entender é o verdadeiro cerne do processo humanizante. Para o autor o cinema: “... sintoniza com o universo do estudante onde impera uma cultura da emoção e da imagem, tem uma particular utilidade educacional” (BLASCO, 2010, p. 359).

Houve também um relato em que o estudante afirmou que as mulheres atendidas sentem certo constrangimento ao serem atendidas por um homem, o que foi confirmado pela estudante que compunha a sua dupla durante a atividade em que o fato ocorreu.

Um dos alunos referiu haver pouca literatura cientifica publicada sobre a área de fisioterapia em saúde da mulher que comprove a eficácia de técnicas específicas e permite apreender que os sujeitos tem interesse em construir seu conhecimento com base em evidências cientificas, conforme recomendado pela OMS (2009):

\begin{abstract}
Outra coisa que eu senti dificuldade também, não sei se fui só eu que senti isso, mas nas próprias aulas teóricas, eu via elas como pouco técnicas ou pouco científicas, eu não via muito como nas outras áreas, talvez por falta de publicações e muitos estudos exaustivos pra comprovação, ainda ta muito no empírico. Algumas técnicas... é bom, é confortável... a mulher se sente melhor, mas até na hora de tirar as duvidas isso e tudo que a gente ia fazer, procurava um artigo, tentava ler pra tentar embasar e até pra tentar entender o que eu estava fazendo por que muitas das coisas que eu vi até hoje eu fico meio assim, ainda não vi a comprovação direito, a fisiologia daquele recurso, é mais a comprovação clinica né, a gente vê muitas vezes que a clinica é soberana, mas a gente te que ter esse embasamento por trás, por que na verdade eu me sinto insegura pra explicar pra pessoas, ah é isso é isso. Fazer a gente já tem a técnica, a prática, mas eu sinto um pouco de dificuldade nas próprias aulas teóricas... (E17)
\end{abstract}

No entanto em busca rápida busca na base de dados da Lilacs usando os descritores fisioterapia; saúde da mulher; parto humanizado foram encontrados 68 trabalhos, entre Dissertações e Teses, Artigos e Livros os quais descrevem a atuação deste profissional tanto a nível da atenção básica com mulheres grávidas ou puérperas quanto a nível hospitalar. 
Os alunos parecem estar a busca de estudos que comprovem a utilização de recursos fisioterapêuticos, porém não devem saber procurar.

A Eletroestimulação Transcutânea, é um exemplo disso. Seus efeitos já foram demonstrados em estudos científicos, e é indicada por diversos autores como conduta a ser realizada durante o parto, uma vez que é uma alternativa que não oferece riscos e que na prática clínica obtém resultados satisfatórios frequentemente relatados pelas parturientes (BARACHO, 2014, BAVARESCO et al., 2011, STEPHENSON; O'CONNOR, 2004).

Canesin e Amaral (2010) realizaram pesquisa em bases de dados e concluíram que o uso da cinsioterapia durante as fases de parto é polemica e que não há um protocolo estabelecido. Apesar disto, a OMS (2009) recomenda como práticas úteis que devem ser estimuladas pela equipe de assistência ao parto, métodos não invasivos e não farmacológicos de alívio da dor, como massagens e técnicas de relaxamento, liberdade de posição e movimento de parto e estímulo a posições não supinas, e classifica o uso de eletroestimulação para o alívio da dor durante o trabalho de parto como prática sem evidências que apoiem uma recomendação clara e que deve ser utilizada com cautela até que sejam comprovadas cientificamente.

Como se pode perceber, a atuação do fisioterapeuta como componente da equipe de parto humanizado é ainda um caminho a ser percorrido, mas que pode contribuir grandemente para o avanço no sentido de um parto natural e com o mínimo de intervenções.

\section{CONSIDERAÇÕES FINAIS}

Ao refletirmos sobre a formação para a humanização em saúde vamos de encontro a cultura atual em que há uma tentativa de padronização dos eventos naturais e até mesmo de comportamentos humanos. Sendo assim, é tema complexo, uma vez que além disso, engloba diversos fatores que precisam ser abordados de maneira mais aprofundada, considerando-se que envolve o coletivo e que as atitudes e escolhas individuais sofrem influência de histórias de vida, experiências, além de questões sociais e de gênero.

Neste sentido, esta quebra de paradigmas depende do interesse e empenho de cada um dos atores envolvidos e o caminho em busca da humanização será completado a medida que ocorra o amadurecimento da sociedade, considerando-se que é um percurso que reúne diversos componentes além da assistência ao paciente e que para isso, não basta apenas investimentos em estruturação de espaços físicos, sendo fundamental o esforço no sentido de buscar uma formação dos profissionais de saúde que contemple essa realidade na prática.

A este propósito, devemos buscar alternativas para melhorar a graduação em fisioterapia, no que tange a saúde da mulher, a fim de gerar conhecimentos, habilidades e atitudes que favoreçam o aprendizado do parto humanizado e sem intervenções farmacológicas, dentre as alternativas sugerimos: Melhorar o ensino da ética em saúde da mulher, promover seminários integrados multiprofissionais e estimular atividades em grupo, ensino através de simulações em simuladores e/ou em pacientes atores, uso de recursos de vídeos, problematização, tutorias, ensino de habilidades do parto normal, treinamentos em serviços, roda de conversa com parteiras. A saúde da mulher deveria ser um tema presente em vários momentos do curso e não apenas alguns momentos durante determinadas disciplinas, pois o parto humanizado é uma competência emergente compatível com as atividades do fisioterapeuta.

De acordo com Rios (2009), a humanização enquanto política publica demonstra menos o que fazer e mais como fazer, neste sentido, são apontadas questões que merecem atenção e que podem e devem ser trabalhadas e debatidas desde a graduação, como o trabalho em equipe, valorizando-se a transdisciplinariedade; a promoção do cuidado (pessoal e institucional) ao cuidador; a valorização da subjetividade e do social tanto no 
cuidado quanto na gestão e a utilização de informação, comunicação, educação permanente e dos espaços na construção de autonomia e protagonismo.

Nosso estudo permitiu conhecer a percepção dos estudantes de fisioterapia da UEPA sobre o atendimento do fisioterapeuta a mulheres em trabalho de parto e sobre as disciplinas que viabilizam a formação acadêmica voltada para o atendimento de fisioterapia no contexto do SUS, em especial em Fisioterapia na Saúde da Mulher. Entendemos que os estudantes tiveram a capacidade crítica de analisar sua formação para atuar na área de assistência ao parto humanizado. Além disso, demonstraram interesse em buscar melhorias para a sua formação e contribuir para a formação de profissionais qualificados para oferecer assistência de qualidade a sociedade.

Consideramos que a discussão/vivencia da humanização durante a formação é plantar uma semente para que no futuro possamos caminhar em direção a um SUS cada vez mais próximo na pratica da beleza presente em sua teoria. 


\section{REFERÊNCIAS}

ANDRADE, M.A.C.; LIMA, J.B.M.C. O modelo obstétrico e neonatal que defendemos e com o qual trabalhamos. In BRASIL, Ministério da Saúde. Humanização do parto e do nascimento. Brasília, DF, 2014. (Cadernos HumanizaSUS: v.4.)

AYRES, J. R. C. M. Hermenêutica e humanização das práticas de saúde. Ciência \& Saúde Coletiva, São Paulo, v. 10, n. 3, p. 549-560, 2005.

BARACHO, E. Fisioterapia Aplicada à Saúde da Mulher. 5ed. Rio de Janeiro: Guanabara-Koogan, 2012, 464p.

BARDIN, L. Análise de Conteúdo. São Paulo: Ed. 70, 2011.

BAVARESCO, G. Z.; SOUZA, R. S. O.; ALMEIDA, B.; SABATINO, J. H.; DIAS, M. O fisioterapeuta como profissional de suporte à parturiente. Ciência \& Saúde Coletiva, Rio de Janeiro, v.16, n 7, p. 3259-3266, 2011.

BIO, E,R, Intervenção fisioterapêutica na assistência ao trabalho de parto. 2007. 149p. Dissertação (Mestrado em Ciências) - Faculdade de Medicina da Universidade de São Paulo. São Paulo, 2007.

BLASCO, P. G. É possível humanizar a Medicina? Reflexões a proposito do uso do Cinema na Educação Médica. O Mundo da Saúde, São Paulo:, v. 3, n. 34, p.357-367, 2010.

BRANDÃO A; GASPARETTO A; PIVETTA H; A fisioterapia na atenção básica: atuação com gestantes em caráter coletivo. Fisioterapia Brasil, Rio de Janeiro, v.9, n. 2, p. 86-92, 2008.

BRASIL. Ministério da Saúde. Humaniza SUS: gestão participativa e cogestão. Textos Básicos de Saúde, on line. Brasília, DF, 2004.

BRASIL. Ministério da Saúde. Parto, aborto e puerpério: assistência humanizada à mulher. Brasília, DF, 2001.

BRASIL. Ministério da Saúde. Programa Nacional de Humanização da Assistência Hospitalar. Brasília, DF, 2000.

CANESIN, K. F.; AMARAL, W. N. Atuação fisioterapêutica para diminuição do tempo do trabalho de parto: revisão de literatura. Femina, Brasília, v. 38, n. 8, p.429-433, ago. 2010.

CASETE, J. C.; CORRÊA, A. K. A humanização do cuidado na formação dos profissionais de saúde nos cursos de graduação. Revista da Escola de Enfermagem da USP, v.46, n. 1, p. 219-226, 2012.

CASSOL, E. G. M.; CANFIELD, J. T.; MORAIS, E. N. Desempenho motor e emocional de parturientes durante o $2^{\circ}$ período do trabalho de parto. Revista Brasileira de Fisioterapia, v.5, n. 1, p. 9-16.

CASTRO, J. C.; CLAPIS, M. J. Parto Humanizado nas perspectivas das enfermeiras obstétricas envolvidas com a assistência ao parto. Revista Latino-americana de Enfermagem, v.13, n.6, p. 960-7, 2005.

CIRNE, S. L.. Humanizar para a saúde gestacional; o papel do fisioterapeuta. 2009. 51 f. TCC (Graduação) - Curso de Fisioterapia, Orientadora: Prof. Ivone Brauns. Universidade Veiga de Almeida, Rio de Janeiro, 2009.

DIAS, M. A. B. Humanização da assistência ao parto: Conceitos, Lógicas e Práticas no cotidiano de uma Maternidade Pública. Fio Cruz, Rio de Janeiro, 2006. 
DIAS, M. A. B.; DESLANDES, S. F. Expectativas sobre a assistência ao parto de mulheres usuárias de uma maternidade pública do Rio de Janeiro, Brasil: os desafios de uma política pública de humanização da assistência. Cadernos de Saúde Pública, Rio de Janeiro, v. 12, n 22, p.2647-2655, 2006.

DINIZ, C. S. G. Humanização da assistência ao parto no Brasil: os muitos sentidos de um movimento. Ciência e Saúde Coletiva. Rio de Janeiro, v. 10, n. 3, 2005.

ERDMANN, A. et al. O Olhar dos Estudantes sobre sua Formação Profissional para o Sistema Único de Saúde. Acta Paulista de Enfermagem, São Paulo, v. 22, n. 3, mai.jun. 2009.

GATTI, B. A. Grupo focal na pesquisa em ciências sociais e humanas. Brasília: Líber Livro, 2005.

LIMA, R. de C. D. SUS e as Teias de Diálogos (im)pertinentes para transformar a formação dos trabalhadores de saúde com vistas à humanização das práticas. Interface: Comunicação, Saúde, Educação, v. 13, supl. 1, p. 781-95, 2009.

LÜDKE, M. e ANDRÉ, M.E.D.A. Pesquisa em educação: abordagens qualitativas. Ed. Pedagógica e Universitária, São Paulo, 2012.

MARTINS, M.C.F.N; BÓGUS, C.M. Considerações sobre a metodologia qualitativa como recurso para o estudo das ações de humanização em saúde. Revista Saúde e Sociedade, v. 13, n 3, p. 44-57, 2004.

MAZZALI, L; GONÇALVES R. N.; Análise do tratamento fisioterapêutico na diminuição da dor durante trabalho de parto normal. Ensaios e Ciência: Ciências Biológicas, Agrárias e da Saúde. São Paulo, SP, v. 12, n. 1, p. 7- 17, 2008.

MOREIRA, M.A. Afinal o que é aprendizagem significativa? 2012. Disponível em http://www.if.ufrgs. br/ moreira/oqueeafinal.pdf. Acesso em 27/01/2016

MORETTI-PIRES, R. O.; BUENO, S. M. Villela. Freire e formação para o Sistema Único de Saúde: o enfermeiro, o médico e o odontólogo. Acta Paul Enfermagem, São Paulo, v. 4, n. 22, p.439-44, 2009.

MOURA, F. M. J. S. P.; CRIZOSTOMO, C. D.; NERY, I. S.; MENDONÇA. R. C. M.; ARAÚJO, O. D.; ROCHA, S. S. A humanização e a assistência de enfermagem ao parto normal. Revista Brasileira de Enfermagem, Brasília, DF, v. 60, n. 4, p. 452-455, 2007.

MOYSÉS, S. T.; MOYSÉS, S. J.; KRIGER, L.; SCHMITT, E. J. Humanizando a educação em Odontologia: Uma pratica educativa humanizada na área da Saúde coloca o homem como centro do processo de construção da cidadania. Revista da Abeno, Londrina, v. 1, n. 3, p.58-64, 2003.

PELIZZARI, A; KRIEGL, M.L.; BARÓN, M.P.; FINK, N.T.L.; DOROCINSKI, S. I. Teoria da aprendizagem significativa segundo Ausubel. Rev. PEC, Curitiba, v.2, n.1, p.37-42, jul. 2001-jul. 2002

ORGANIZAÇÃO MUNDIAL DE SAÚDE (OMS). Disponível em: http://abcdoparto.com.br/site/assistenciaao-parto-normal/. Acesso em: 22 de janeiro de 2013.

PARÁ, UniVERsidAde DO ESTADO DO PARÁ (UEPA), Projeto Pedagógico do Curso de Fisioterapia, 2008.

PETRI, F.C. História e Interdisciplinaridade no processo de humanização da fisioterapia. 2006. 80 f. Dissertação - Universidade Federal de Santa Maria - UFSM [2006].

REGO, S.; GOMES, A. P.; SIQUEIRA-BATISTA, R. Bioética e Humanização como Temas Transversais na Formação Médica. Revista Brasileira de Educação Médica, v. 32, n. 4, p. 482-491, 2008. 
RIBEIRO, K. S. Q. S. A contribuição da extensão comunitária para a formação acadêmica em fisioterapia. Fisioterapia e Pesquisa, v. 12, n. 3, 2005.

RIOS, I. C. Humanização: a essência da ação técnica e ética nas praticas de saúde. Revista Brasileira de Educação Médica, v. 33, n. 2, p. 253-261, 2009.

ROSSONI, E; LAMPERT, J. Formação de profissionais para o Sistema Único de Saúde e as diretrizes curriculares. Boletim da Saúde, Porto Alegre, v. 18, n. 1, p.87-98, 2004.

SEIBERT, S. L.; BARBOSA, J. L. S.; SANTOS, J, M; VARGENS, O. M. C. Medicalização x Humanização: o cuidado ao parto na história. Revista de Enfermagem da UERJ, Rio de Janeiro, v. 13, p. 245-51, 2005.

SILVA, F. D.; CHENICHARO, I. M.; FERREIRA, M. A. Humanização e desumanização: a dialética expressa no discurso de docentes de enfermagem sobre o cuidado. Escola Anna Nery, v. 15, n. 2, p. 306-313, abr./jun. 2011.

SILVA, I.D.; SILVEIRA, M. F. A. A humanização e a formação profissional em fisioterapia. Ciência \& Saúde Coletiva, Rio de Janeiro, v.16, p. 1535-1546, 2011.

SOUZA L; Alves R; Gonçalves R; Caldeira V, Maria F; Fisioterapia durante a gestação: um estudo comparativo. Fisioterapia. Brasil; v. 6, p. 265-270, 2005.

STEPHENSON, R.; O’CONNOR, L. Fisioterapia Aplicada à Ginecologia e Obstetrícia. $2^{\mathrm{a}}$ ed. São Paulo: Manole, 2004.

SUMIYA, A.; JEOLÁS, L. S. Processos de mudança na formação do fisioterapeuta: as transições curriculares e seus desafios. Acta Scientiarum: Human and Social Sciences, Maringá, v. 32, n. 1, p. 47-53, 2010.

TORNQUIST, C. S. O Parto Humanizado e a REHUNA. Anais do II Seminário Nacional Movimentos Sociais, Participação e Democracia. Florianópolis, p. 145-60, 2007. 